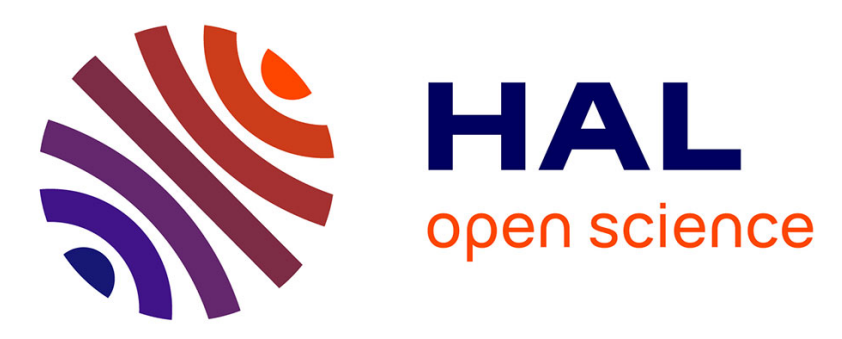

\title{
All-solid aperiodic Large Pitch Fibers for operation in high power regime
}

\author{
Romain Dauliat, Dia Darwich, Aurélien Benoit, Raphaël Jamier, Stephan \\ Grimm, Kay Schuster, François Salin, Philippe Roy
}

\section{- To cite this version:}

Romain Dauliat, Dia Darwich, Aurélien Benoit, Raphaël Jamier, Stephan Grimm, et al.. All-solid aperiodic Large Pitch Fibers for operation in high power regime. 17th International Conference on Transparent Optical Networks (ICTON), Jul 2015, Budapest, Hungary. 10.1109/ICTON.2015.7193357 . hal-01250260

\section{HAL Id: hal-01250260 \\ https://hal.science/hal-01250260}

Submitted on 4 Jan 2016

HAL is a multi-disciplinary open access archive for the deposit and dissemination of scientific research documents, whether they are published or not. The documents may come from teaching and research institutions in France or abroad, or from public or private research centers.
L'archive ouverte pluridisciplinaire HAL, est destinée au dépôt et à la diffusion de documents scientifiques de niveau recherche, publiés ou non, émanant des établissements d'enseignement et de recherche français ou étrangers, des laboratoires publics ou privés. 


\title{
All-solid aperiodic Large Pitch Fibers for operation in high power regime
}

\author{
Romain Dauliat ${ }^{1,2}$, Dia Darwich ${ }^{1}$, Aurélien Benoît ${ }^{1,3}$, Raphaël Jamier ${ }^{1}$, Stephan Grimm ${ }^{2}$, Kay Schuster ${ }^{2}$, \\ François Salin ${ }^{3}$ and Philippe Roy ${ }^{1}$ \\ ${ }^{1}$ Univ. Limoges, CNRS, XLIM, UMR 7252, F-87000 Limoges, France \\ ${ }^{2}$ Institute for Photonic Technology, Albert Einstein Str. 9, 07745 Jena, Germany \\ ${ }^{3}$ Eolite systems, 11 avenue de la Canteranne, 33600 Pessac, France \\ Tel: (+0033) 555457 268, e-mail: romain.dauliat@xlim.fr
}

\begin{abstract}
This communication intends to summarize the recent strides carried out by the study of original Very Large Mode Area fibers (VLMA) that offer remarkable beam qualities. This work also aims in pushing farther the threshold of appearance for non-linear processes as well as thermal induced beam degradation hindering the power scaling in optical fibers. So as to fulfil this objective, thorough investigations of fibers modal content has been performed, leading to the evidencing of primordial statements for exacerbation of the beam quality and its robustness. Theoretical principles driven toward the conception of aperiodic Large Pitch Fibers (LPFs) will be reported together with experimental validation into passive fiber designs. The relevance of these original structures will then been discussed in regard to the power scaling.
\end{abstract}

Keywords: High power regime, Fiber laser and amplifiers, aperiodic Large Pitch Fiber, Singlemodedness, thermal induced refractive index changes.

\section{INTRODUCTION}

Microstructured optical fibers designs are undergoing an outstanding infatuation since two decades now owing to the versatility of the 'stack and draw' technique and recent progress in producing high quality glass. In particular, the development of high power singlemode laser sources has attracted much interest on them, resulting in no less than a tenth of novel microstructured fiber concepts competing to provide further power scaling of singlemode radiation toward the $\mathrm{kW}$ regime. Among them, one may have noticed three major categories: 1/ 'Photonic Bandgap' designs such as the Bragg or hetero-structured 2D PBG fibers [1,2], $2 /$ resonantly coupling geometry like the Chirally Coupled Core fibers or Distributed Mode Filtering fibers $[3,4]$ and leaky structures represented by the state-of-the-art air-silica Large Pitch Fibers (LPF) [5]. Although requiring to be used as rod-type owing to their critical bending sensitivity, Large Pitch Fibers are one of a kind geometry that already demonstrated singlemode operation into active fibers of Mode Field Area reaching up to $10,000 \mu \mathrm{m}^{2}$ whereas most of their counterparts barely exceed 2,500 $\mu \mathrm{m}^{2}$ [1-3]. This enabled a leap in power/energy attaining $26 \mathrm{~mJ}$ - sub $60 \mathrm{~ns}$ pulses from a Q-switched fiber laser sources [6] as well as $22 \mathrm{GW}$ peak power in a chirped-pulse amplification configuration [7]. However, high power fiber lasers still suffer from two main issues: 1/ the photodarkening, resulting in a progressive increase of the background losses and $2 /$ thermal induced modal instabilities that restrain the power scaling by implying a significant degradation of the beam quality over a certain power threshold [8].

\section{DESCRIPTION OF THE FIBER CONCEPT}

This work has thus been structured around principles aiming to bring simplicity during the fiber/laser realization and offer headways to mitigate the two-abovementioned key hurdles hampering the power scaling. To do so, we opted for the preparation of all-solid structures, facilitating the fiber splicing and cleaving, by resorting to an innovative manufacturing process named Repusil [9]. The latter allows for producing highly homogeneous and reproducible doped-glass with an accuracy of $2.10^{-4}$, being much precise than any conventional CVD techniques. Thus, authors strongly believe that this technique will permit the preparation of VLMA fibers having a perfect index matching between the actively doped region and the surrounding material. For now on, most of the fibers enumerated in the introduction must be based on an active glass index-matched with the pure silica, limiting the concentration in rare-earth and requiring the use of index depressive co-dopant as fluorine. By opposition, we decided to get freed from this constraint by using a passively doped silica cladding (in blue on Fig.1a) whose the refractive index matches that of the gain material (in red on Fig.1a). Thus, the active glass can exhibit a strong rare-earth concentration (and so on a higher single-pass gain) and be judiciously co-doped with Ce or P for photodarkening mitigation without restriction on its refractive index [10]. Then, an inner cladding microstructuration made of solid inclusions (in cyan on Fig.1a), the geometry of which will be discussed in section 3, is implemented to ensure a selective amplification of the fundamental mode (FM) while efficiently delocalizing the high-order-modes ( $\mathrm{HOM})$ out of the gain region. The extension of the passively doped silica is 
limited by a pure silica jacket (in navy blue on Fig.1a) so as to restrict the number of guided cladding modes. Finally, a third clad is employed for the propagation of the pump radiation, resulting thus in a triple clad design.

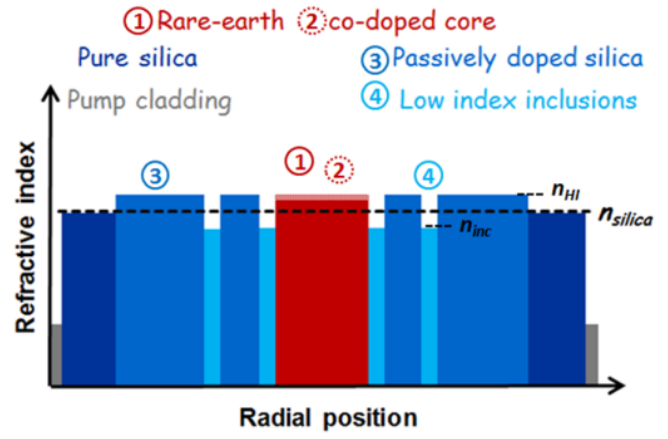

(a)

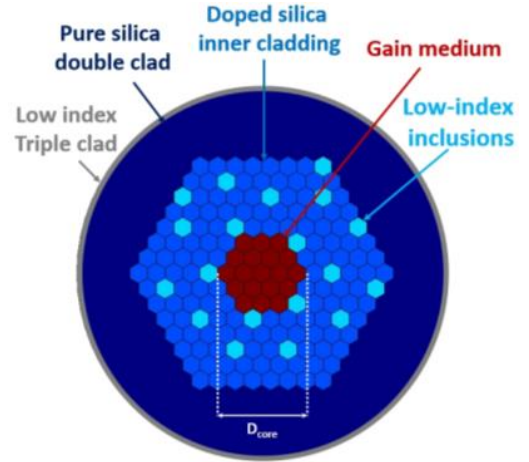

(b)

Figure 1. (a) Transverse refractive index profile of the proposed all-solid Large-Pitch Fibers in which the passively doped silica of the first cladding matches that of the active region. Numbers identify the index evolutions along the description of the section 2. (b) Cross section of an all-solid triple-clad Fully-Aperiodic Large-Pitch fiber overlaid by an artificial grid that schematically represents the stack.

\section{TAILORING THE INNER CLADDING MICROSTRUCTURATION}

The fiber design was initially inspired from that of LPFs as they can be considered as the current reference for HOM rejection. Hence, the concern was to evidence key geometrical principles essential to the confinement of the FM into the gain region along with those offering an exacerbation of the HOM delocalization out of the core. We have first demonstrated that only the first layer of inclusions surrounding the gain region (see Fig. 1b) is involved into the confinement of the FM [11]. Indeed, inclusions localized farther into the doped silica region act mostly in preventing the risk of 'avoided crossing', that is a coupling between the core FM and any cladding modes. This process can occur if the two modes exhibit a spatial intensity overlap and close index values. Thus, we have demonstrated that periodic inner cladding microstructuration are not desirable since they favour the energy transfer between modes of same symmetry class as current leaky fibers do. Thereby, the suppression of the cladding symmetry might minimize the potential of avoided crossing owing to limited modes overlap.

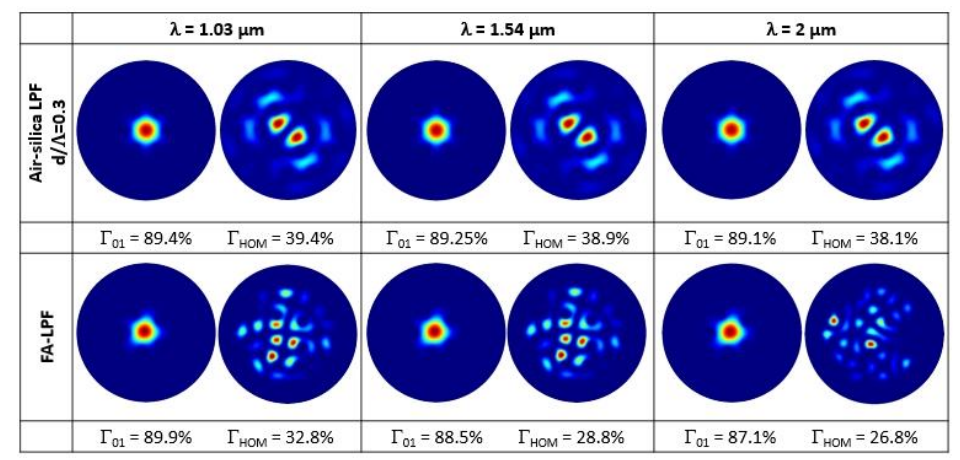

Figure 2. Comparison of the fundamental and most confined high order modes intensity pattern into an $85 \mu \mathrm{m}$ state-of-the-art air-silica LPF having a normalized holes size of 0.3 and a $85 \mu \mathrm{m}$ core Fully-Aperiodic LPF. The overlap factors of each displayed modes are reported.

These statements have thus led to the realization of Fully-Aperiodic Large-Pitch-Fibers (FA-LPF). It is worth noticing that a great flexibility is offered by the stack-and-draw technique in developing such kind of original structures. Although several efficient FA-LPF has been conceived [12-13], only one specific geometry will be discussed thereafter to clarify the purpose (see Fig. 1b). This design is based on 5 inclusions forming an irregular pentagon in close vicinity to the gain region and 14 additional inclusions acting on the cladding mode content. The quality of the propagated beam was estimated by computing the overlap $\Gamma$ of the first 300 guided modes with the gain region and then determining the difference in overlap between the FM core mode and the most competitive HOM. This parameter is called 'Modal discrimination' and referred to as $\Delta \Gamma$. One must know that a singlemode operation is commonly stated when $\Gamma$ exceeds $80 \%$ while $\Delta \Gamma$ is greater than $30 \%$. As an example, air-silica LPFs satisfy these criteria over a wide range of core sizes and operating wavelengths with a discrimination of about 50\%. In comparison, FA-LPFs improve the modal discrimination by up to $11.5 \%$ as can be seen on Fig. 2 while conserving a strong confinement of the FM $(\Gamma>87 \%)$. 


\section{EVIDENCING OF ROBUST SINGLEMODE PROPAGATION INTO APERIODIC LARGE-PITCH FIBERS}

First fabrications of passive FA-LPFs have been then undertaken to corroborate the outstanding performances established numerically. The quality of the transmitted beam has been assessed from two ways: by achieving Optical Low Coherence Interferometry (OLCI) measurements, and by observing the near-field pattern over a wide range of core sizes and operating wavelengths (Fig.3b). One can notice on Fig.3a that the sole FM has been identified at $1300 \mathrm{~nm}$ during the OLCI measurements achieved on $85 \mu \mathrm{m}$ core FA-LPFs, confirming the high purity of the transmitted beam. Nevertheless, although a singlemode operation has been obtained for a core diameter reaching up to $140 \mu \mathrm{m}$ at an operating wavelength of $2 \mu \mathrm{m}$, the singlemode range is not as wide as estimated numerically. Indeed, the performances were degraded by residual stress that led to the guidance of a supermode as can be seen on the top-left inset of Fig. 3b. New fabrications are on underway to improve this result. Additionally, the singlemode robustness will also be addressed at the conference time by showing that the near-field pattern remains unchanged when the launched beam is shifted across the fiber core, except for a variation in intensity.

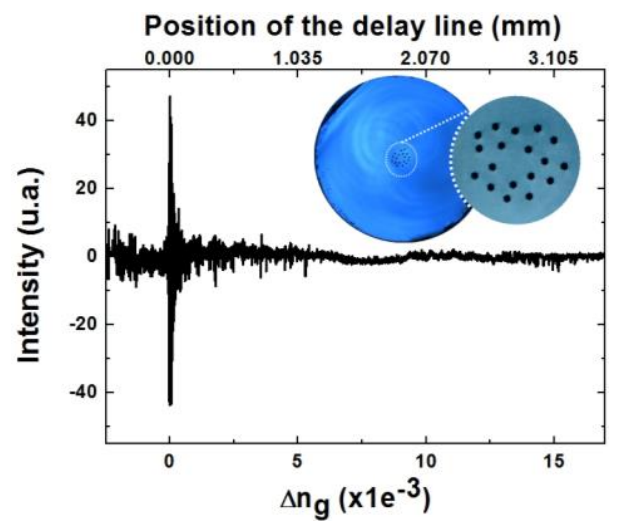

(a)

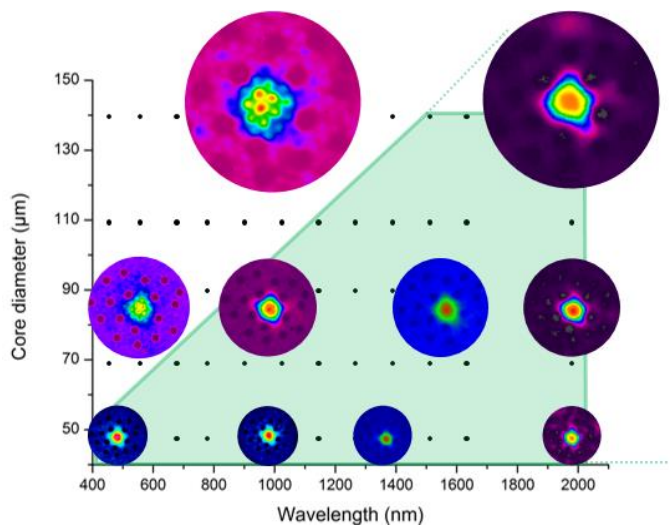

(b)

Figure 3. (a) OLCI trace recorded at the output of an $85 \mu \mathrm{m}$ core Ap. LPF using a $10 \mathrm{~nm}$ bandpass filter at $1300 \mathrm{~nm}$ versus the difference in group refractive index and the position of the delay stage. Inset: Cross section of the manufactured simple clad FA-LPF. (b) Evolution of the measured near-field intensity pattern versus the operating wavelength and the core size. The green area stands for the range of robust singlemode propagation.

\section{PERFORMANCE OF FULLY APERIODIC LPF AT HIGH POWER REGIME}

So as to determine the benefit of FA-LPF for high power operation, it was primordial to discuss their performances in regard to the heat load ' $\mathrm{q}$ ', which is directly related to the amount of absorbed power: $P_{a b s}=q /(1-\eta)$, with $\eta$ being the quantum efficiency of the gain medium. With the power scaling, the heat load progressively modifies progressively the refractive index profile of the waveguide, inducing a quadratic trend in the gain region and logarithmical decay elsewhere. Thus, it impacts directly the modal content of optical fibers. A novel optimization of the abovementioned FA-LPF appeared then beneficial so as to extend as much as possible the range of singlemodedness. The optimized FA-LPF design, reported on Fig.4a, displayed a modification of the irregular pentagon surrounding the gain region, yielding in an even higher mode leakage.

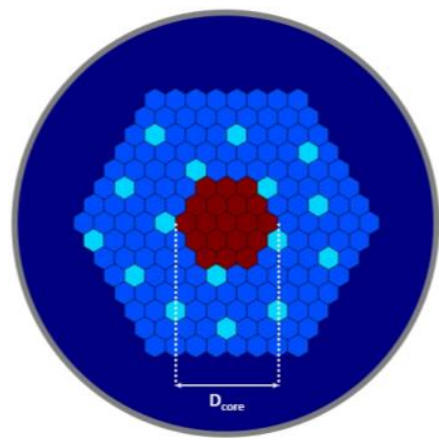

(a)

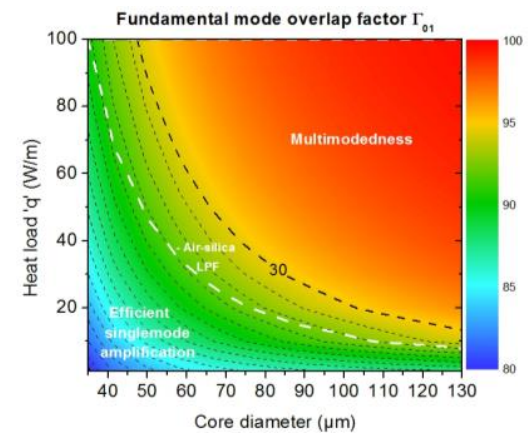

(b)

Figure 4. (a) Graphical representation of an all-solid triple-clad Fully-Aperiodic Large-Pitch fiber optimized for high power operation. (b) Evolution of the FM overlap factor versus the pitch $\Lambda$ and the heat load ' $q$ '. The black dashed line represents the limit of singlemodeness $(\Delta \Gamma=30 \%)$ into this fiber whereas the white one depict it for a state-of-the-art air-silica $L P F$. 
Fig 4b shows how the overlap of the FM evolves when tuning the core size and the heat load. An efficient amplification is experienced over the whole range of investigation since $\Gamma_{01}$ exceeds $80 \%$. Hence, the limit of effective singlemode operation - so the point at which the modal discrimination becomes lower than $30 \%$ - is depicted for an air-silica LPF of 0.3 in normalized holes size (white dashed line on Fig.4a) and the optimized FA-LPF (Thick black dashed line on Fig.4a). It is worth noticing that the range of efficient singlemode amplification (dashed region) has been effectively extended, increasing by half the maximum heat load sustainable while keeping a singlemode emission.

\section{CONCLUSIONS}

We have reported on optical waveguides featured by an innovative aperiodic cladding design ensuring an emphasized High Order Modes (HOMs) rejection out of the gain region while preserving an efficient amplification of the Gaussian-like fundamental mode. Their outstanding beam purity was first demonstrated analytically and then corroborated by OLCI measurements on passive fibers. The potential of these design was finally discussed taking into account the thermal load related to the power scaling. This shows an improvement by half of the sustainable heat power before onset of beam degradation.

\section{ACKNOWLEDGEMENTS}

This work, conducted under the frame of the AVANTAGE project, was co-funded by the European Union and Eolite Systems. EC is involved in the Région Limousin with the "Fonds européen de développement économique et régional". We also acknowledge the ANR (Agence Nationale de la Recherche) for funding the project UBRIS2 thought which this work has been done.

\section{REFERENCES}

[1] D. A. Gaponov, S. Février, M. Devautour, P. Roy, M. E. Likhachev, S. S. Aleshkina, M. Y. Salganskii, M. V. Yashkov, and A. N. Guryanov, "Management of the high-order mode content in large $(40 \mu \mathrm{m})$ core photonic bandgap Bragg fiber laser," Opt. Lett., vol. 35, no. 13, pp. 2233-5, Jul. 2010.

[2] A. Baz, L. Bigot, G. Bouwmans, and Y. Quiquempois, "Single-mode, large mode area, solid-core photonic bandgap fiber with hetero-structured cladding," J. Light. Technol., vol. 31, no. 5, pp. 830-835, 2013.

[3] X. Ma, C. Zhu, I.-N. Hu, A. Kaplan, and A. Galvanauskas, "Single-mode chirally-coupled-core fibers with larger than 50 $\mu \mathrm{m}$ diameter cores," Opt. Express, vol. 22, no. 8, p. 9206, 2014.

[4] M. Laurila, R. Barankov, M. M. Jørgensen, T. T. Alkeskjold, J. Broeng, J. Lægsgaard, and S. Ramachandran, "Cross-correlated imaging of single-mode photonic crystal rod fiber with distributed mode filtering," Opt. Express, vol. 21, no. 8, p. 9215, 2013.

[5] J. Limpert, F. Stutzki, F. Jansen, H.-J. Otto, T. Eidam, C. Jauregui, and A. Tünnermann, "Yb-doped largepitch fibres: effective single-mode operation based on higher-order mode delocalisation," Light Sci. Appl., vol. 1, p. e8, 2012.

[6] F. Stutzki, F. Jansen, A. Liem, C. Jauregui, J. Limpert, and A. Tünnermann, "26 mJ, 130 W Q-switched fiber laser system with near-diffraction-limited beam quality," Opt. Lett., vol. 37, no. 6, pp. 1073-1075, 2012.

[7] A. Klenke, S. Hädrich, T. Eidam, J. Rothhardt, M. Kienel, S. Demmler, T. Gottschall, J. Limpert, and A. Tünnermann, "22 GW peak-power fiber chirped-pulse-amplification system," Opt. Lett. 39, 68756878 (2014).

[8] T. Eidam, C. Wirth, C. Jauregui, F. Stutzki, F. Jansen, H.-J. Otto, O. Schmidt, T. Schreiber, J. Limpert, and A. Tünnermann, "Experimental observations of the threshold-like onset of mode instabilities in high power fiber amplifiers," Opt. Express, vol. 19, no. 14, pp. 13218-24, 2011.

[9] A. Langner, T. Kayser, G. Schoetz, M. Such, J. Kirchhof, S. Grimm, and V. Reichel, "Method for producing doped quartz glass," 2010.

[10] S. Jetschke, S. Unger, A. Schwuchow, M. Leich, and J. Kirchhof, "Efficient Yb laser fibers with low photodarkening by optimization of the core composition," Opt. Express, vol. 16, no. 20, pp. 15540-15545, 2008.

[11] R. Dauliat, A. Benoît, R. Jamier, K. Schuster, S. Grimm, F. Salin, and P. Roy, "Striving towards a periodicity breaking of the photonic crystal cladding microstructuration for an unprecedented singlemode robustness," in Proc. SPIE 9128, Micro-structured and Specialty Optical Fibres III, 2014, p. 912807.

[12] A. Benoît, R. Dauliat, R. Jamier, G. Humbert, S. Grimm, K.Schuster, F. Salin, and P. Roy, "Highly efficient higher-order modes filtering into aperiodic very large mode area fibers for single-mode propagation," Opt. Lett. 39, pp. 4561, 2014.

[13] R. Dauliat, D. Gaponov, A. Benoît, F. Salin, K. Schuster, R. Jamier, and P. Roy, "Inner cladding microstructuration based on symmetry reduction for improvement of singlemode robustness in VLMA fiber," Opt. Express, vol. 21, no. 16, pp. 18927-18936, 2013. 